\title{
Postal consent for upper gastrointestinal endoscopy
}

\author{
H A Shepherd, D Bowman, B Hancock, J Anglin, D Hewett
}

\begin{abstract}
Background-Standards for good practice in clinical risk management issued by the Clinical Negligence Scheme for Trusts indicate that "appropriate information is provided to patients on the risks and benefits of proposed treatment, and of the alternatives available before a signature on a consent form is sought".

Aims-To investigate the practicability and patient acceptability of a postal information and consent booklet for patients undergoing outpatient gastroscopy.

Methods-Information about gastroscopy procedure, personalised appointment details, and a carbonised consent form were compiled into a single booklet. This was mailed to patients well in advance of their endoscopic procedure. Patient satisfaction for this new process was assessed by questionnaire.

Results-275 patients received a patient information booklet. Of these, 150 (54.5\%) returned the consent form by post when they confirmed their attendance; 141 (94\%) had signed the form, and the other nine requested further information. Of the remaining 125 booklets sent out, 115 $(92 \%)$ forms were brought back on the day of the investigation having been previously signed. The remaining $10(8 \%)$ required further information before signing the form. An audit of 168 patients was used to test reaction to the booklet and the idea of filling in the form before coming to hospital; 155 patients $(92.2 \%)$ reported the information given in the booklet to be "very useful", and all reported it to be "clear and understandable".

Conclusion-A specifically designed patient information booklet with integral consent form is accepted by patients, and improves the level of understanding prior to the investigation being carried out. (Gut 2000;46:37-39)
\end{abstract}

Gastrointestinal Unit, Royal Hampshire

County Hospital, Romsey Road, Winchester, Hants, UK

H A Shepherd

D Bowman

B Hancock

J Anglin

D Hewett

Correspondence to:

Dr H A Shepherd.

Accepted for publication 2 June 1999 depth and content. Furthermore, some tients will sign consent forms without asking for additional information, especially when they have already gone to the trouble of attending the hospital. The busy clinical environment may well inhibit questions and certainly does not permit much time for deliberation. Consent given in these circumstances has been questioned by senior legal opinion and may be defective if it is not based on sufficient information.

The National Health Service Litigation Authority, through the Clinical Negligence Scheme for Trusts (CNST), seeks to raise standards in the areas of communication with patients, and in gaining informed consent to treatment. The CNST has recently published a manual of 11 principal standards which member Trusts are exhorted to meet in order to achieve a reduction in subscriptions. ${ }^{1}$

Standard 7 states that "appropriate information is provided to patients on the risks and benefits of proposed treatment, and of the alternatives available before a signature on a consent form is sought". The rationale for this flows from the observation that "complaint or litigation is less likely to follow if patients understand to what they are consenting". The Standard then goes on to demand that:

- consent forms conform to National Health Service Executive Guidelines on content and design;

- there is patient information available showing the risks and benefits of proposed procedures; and

- there is a policy guideline stating that consent for elective procedures is to be obtained by a person capable of performing the procedure.

English case law relating to informed consent to treatment provides that there must be prior consultation or discussion. Where this does not take place, the patient, as a matter of law, may be held as not to have consented to treatment. ${ }^{2}$ In practice, however, recent cases which have come to trial have dealt with alleged failure to disclose risks inherent in the treatment, rather than failure to consult the patient. Medical practitioners may be held negligent if they fall below the standard of care practised by a responsible body of medical opinion in drawing their patient's attention to the risks inherent in a given procedure. This is the application of the so called Bolam test to the counselling of patients. ${ }^{3}$

This approach is a pragmatic one which distinguishes English practice from other countries such as the United States. Judges here have tended to uphold a standard of care based on a responsible body of medical practice over the right of the individual patient to know of all risks. $^{2}$ 
Table 1 Results of postal consent trial

\begin{tabular}{llrr}
\hline & Number & $\begin{array}{l}\text { Per cent of } \\
\text { subtotal }\end{array}$ & $\begin{array}{c}\text { Per cent of } \\
\text { total }\end{array}$ \\
\hline Number of booklets sent out & 275 & & 100 \\
Number returned prior to attending for endoscopy. & 150 & & 54 \\
$\quad$ & 141 & 94 & 51 \\
$\quad$ Of these: & 9 & 6 & 3 \\
$\quad$ Number signed & 125 & & 46 \\
$\quad$ Number returned on arrival for endoscopy. & 115 & 92 & 42 \\
$\quad$ Of these: & 10 & 8 & 4 \\
$\quad$ Number signed & & \\
$\quad$ Requiring information & & \\
\hline
\end{tabular}

Table 2 Response to patient questionnaire

\begin{tabular}{llrr}
\hline Question & Response & Number & $\%$ \\
\hline Did you receive the information booklet in & Yes & 168 & 100 \\
advance of your treatment? & No & 0 & 0 \\
Did you find the information: & Very useful & 155 & 92 \\
& Fairly useful & 12 & 7 \\
Did you find the language used clear and & Not very useful & 1 & 1 \\
understandable? & Yes & 168 & 100 \\
Did you fill in the consent form at the back of & No & 0 & 0 \\
the booklet before you came to the hospital? & No & 154 & 92 \\
Where would you prefer to fill in your consent & At home & 14 & 8 \\
form? & In hospital & 129 & 77 \\
& No preference & 8 & 18 \\
& & & 5 \\
\hline
\end{tabular}

As a result, there is no clear guidance as to the level of risk which requires specific mention to patients. Indeed, clinical judgement may indicate that a risk discussed with one patient, may properly be considered inappropriate to mention with another in the same circumstances. For this reason judges in the landmark Sidaway case avoided laying down any specific quantification of risk, relying instead on the professional judgement of doctors and the capabilities of the particular patient concerned. ${ }^{4}$

Taking the CNST standard together with the legal principles into account, it might be suggested that all patients coming for endoscopy should have a prior consultation with a fully trained endoscopist 24 hours before being scheduled for investigation. ${ }^{5}$ This, however, is extremely expensive in terms of skilled resource, and would have the undesirable effect of reducing the availability of a heavily used service, thereby disadvantaging other patients with an urgent need. The British Society of Gastroenterology has stated that such a standard is impossible to achieve.

The use of a postal consent form coupled with an information booklet was therefore investigated as a way of reconciling the individual patient's need to be informed and to consent without being exposed to undue pressure, with the need to investigate as many patients as possible within the shortest time.

\section{Subjects and methods}

In total, 275 patients referred to the open access service for an upper gastrointestinal endoscopy were surveyed.

An information booklet was written by the consultant gastroenterologist and nursing staff. This draft document was submitted to the communications manager (a trained journalist) for subediting. ${ }^{6}$ Colleagues in the legal department reviewed the document and revised text where appropriate, so that this booklet became a valid document for obtaining consent which conforms to NHS Management Executive (NHSE) guidelines. ${ }^{7}$

The booklet was then professionally printed. It incorporated a consent form which was detachable, and self carbonating so that patients could return the top copy and confirm the appointment which had been given. The text of the booklet explained the process of endoscopy, the options regarding sedation and the drugs used, the risks of endoscopy and sedation, the personnel they were likely to encounter and why, and finally the recovery process and procedures relevant to their discharge. Patients who signed the consent form were acknowledging that they were content to proceed with the planned gastroscopy, but this did not ultimately affect their right to change their mind later. To personalise the document, clinic staff wrote in the patient's name and appointment time on the first page of the booklet.

After treatment patients were asked to complete a short questionnaire to indicate their reactions to the booklet and the consent form.

\section{Results}

Table 1 summarises the results. Of the 275 booklets sent out, a high proportion (96.8\%) had been signed, either having been posted or returned by hand on the day of the endoscopy. In all $150(54.5 \%)$ booklets were returned by post having been signed prior to endoscopy. Of the remaining 125 booklets, 115 were brought back on the day of the gastroscopy having been signed prior to coming to hospital. Nineteen patients $(6.9 \%)$ wished to ask for further information and subsequently signed the consent in the endoscopy department, at least 30 minutes before the procedure. Every patient sent a booklet subsequently attended for gastroscopy.

To test whether or not these results represented true satisfaction the patient questionnaire was administered (table 2). The results indicate that $96.8 \%$ of patients were content to sign their forms at home but only $56.6 \%$ posted them back to the unit.

\section{Discussion}

Pereira et al have previously shown that the standard consent form administered immediately prior to endoscopy in hospital was read by only half of the patients attending their service. ${ }^{8}$ Furthermore, doctors tend naturally to write in a style normally associated with medical journals rather than, for example, a tabloid newspaper. ${ }^{9}$

The atmosphere of a busy department just prior to undergoing an unknown procedure is not the best environment in which take in new and complex information. In such circumstances it is easy to remain passive and go with the flow. Morgan et al divided patients into two groups, information seekers and information avoiders on the basis of coping behaviour. Those who sought information would be expected to ask further questions. If the information given was compatible with their coping behaviour there would be less anxiety than 
expected and time spent in recovery would be reduced..$^{10}$

Physicians working in a clinical environment are endowed with considerable authority. The balance of power between professionals and patients is heavily skewed. Taking all these factors together patients are placed at a significant disadvantage.

These results indicate a strong preference for the decision to be taken at a distance from the hospital in familiar circumstances. Satisfying this need requires a well written information booklet which describes the investigation, and prepares the patient for what is to happen. The booklet also describes the common indications for undertaking the procedure and mentions both the common risks involved, and the potential benefits.

The proportion of consent forms returned prior to the investigation being carried out may be increased by supplying prepaid envelopes with the booklets. These results show the system to be popular with patients, and the endoscopy unit staff report that it saves them time, although that benefit has not been measured objectively.

Full text of the booklet is available on the Gut website: www.gutjinl.com

1 Clinical Negligence Scheme for Trusts. Risk management standards and procedures: manual of guidance. National Health Litigation Authority, 1997.

2 Nelson-Jones R, Burton F. Medical negligence case law. 2nd ed. London: Butterworths, 1995:102.

3 Bolam v Friern Hospital Management Committee: McNair Bolam v Friern Hospital Management Committee: McN
J (with jury) [1957] 2 All ER 118, [1957] 1 WLR 582.

4 Sidaway v Board of Governors of Bethlem Royal Hospital and The Maudsley Hospital and Others, House of Lords [1985] AC 871, [1985] 1 All ER 643, [1985] 2 WLR 480.

5 Informed Consent for Endoscopic Procedures. British Society of Gastroenterology guidelines http://www.bsg.org.uk/ guidelines/consent.html.

6 Smith T. Information for patients: writing simple English is difficult, even for doctors. BMF 1992;305:1242.

7 NHS Management Executive. A guide to consent for examination or treatment. $\mathrm{HC}(90) 22$.

8 Pereira SP, Hussaini SH, Wilkinson ML. Informed consent for upper gastrointestinal endoscopy. Gut 1995;37:151-3.

9 Priestly KA, Campbell C, Valentine CB, et al. Are patient consent forms for research protocols easy to read? $B M \mathcal{F}$ 1992;305:1263-4.

10 Morgan J, Roufeil L, Kaushik S, et al. Influence of coping style and pre-endoscopy information on pain and anxiety at colonoscopy. Gastrointest Endosc 1998;48:119-27. 